\title{
ORIGINAL RESEARCH \\ Endovascular Therapy of 500 Small Asymptomatic Unruptured Intracranial Aneurysms
}

H. Oishi

M. Yamamoto

T. Shimizu

K. Yoshida

H. Arai

BACKGROUND AND PURPOSE: Although the natural course of UIAs remains unclear, the risk of aneurysmal SAH due to small $(<10 \mathrm{~mm})$ asymptomatic UIAs is low. Endovascular therapy for UIAs has increased because of device development and the need for less invasive treatment. We report the results, safety, and efficacy of endovascular therapy of small asymptomatic UIAs.

MATERIALS AND METHODS: A total of 457 patients with 500 small asymptomatic UIAs (maximum diameter $<10 \mathrm{~mm}$ ) underwent endosaccular coil embolization at Juntendo University Hospital and affiliated hospitals. We retrospectively evaluated the technical feasibility, immediate and short-tomidterm follow-up anatomic results, procedure-related complications, and clinical outcomes.

RESULTS: Endosaccular coil embolization was completed in 481 aneurysms (96.2\%) and attempted in 19 (3.8\%). Completed aneurysms were treated with the simple (39.5\%), balloon-assisted (51.4\%), and double-catheter (9.1\%) techniques. Immediate angiographic outcomes were CO for 309 (64.2\%) aneurysms, RN for 72 (15.0\%), and RA for 100 (20.8\%). Procedure-related complications occurred in 38 aneurysms (7.6\%): 19 ischemic, 11 hemorrhagic, and 8 others. Permanent morbidity and mortality were $0.8 \%$ and $0.2 \%$, respectively. Anatomic outcome of 427 aneurysms followed up for $>6$ months with conventional catheter or MR angiographies showed recanalization in 72 (16.9\%) aneurysms, necessitating retreatment in $9.9 \%$ (mean, 31.4 months). No patients had aneurysmal SAH during the clinical follow-up period (mean, 34.7 months).

CONCLUSIONS: In this series, endovascular therapy of small asymptomatic UIAs was highly feasible with low morbidity and mortality rates.

\begin{abstract}
ABBREVIATIONS: $\mathrm{ACA}=$ anterior cerebral artery; $\mathrm{AChoA}=$ anterior choroid artery; $\mathrm{AcomA}=$ anterior communicating artery; ATENA = Analysis of Treatment by Endovascular approach of Nonruptured Aneurysms; BA = basilar artery; $\mathrm{CO}=$ complete occlusion; $\mathrm{D} / \mathrm{N}=$ dome-to-neck; GDC = Guglielmi detachable coil; ISUIA = International Study of Unruptured Intracranial Aneurysms; $\mathrm{mRS}=$ modified Rankin Scale; PcomA = posterior communicating artery; RA = residual aneurysm; RN = residual neck; UIA = unruptured intracranial aneurysm
\end{abstract}

$\mathbf{U}$ IAs are increasingly diagnosed due to the development of less invasive and high-quality neuroimaging modalities such as CT angiography and/or MR angiography. Small asymptomatic UIAs have a low risk of aneurysmal rupture. ${ }^{1-3}$ Therefore, the decision to manage small asymptomatic UIAs requires an assessment of the risks of various treatment options and knowledge of the natural course of the disease process. Current evidence does not conclusively justify the conservative management of small asymptomatic UIAs, and the development of endovascular devices and increased experience have significantly reduced the procedure-related risks.

To our knowledge, there was only 1 report dealing with endovascular therapy of small asymptomatic UIAs. ${ }^{4}$ Therefore, precise risk evaluations of endovascular therapy of small asymptomatic UIAs have not yet been established. The purpose of this study was to report the treatment results of endovascular therapy of small asymptomatic UIAs and to elucidate the procedural feasibility, clinical outcomes, and procedurerelated risks.

Received May 3, 2011; accepted after revision July 21.

From the Department of Neurosurgery, Juntendo University School of Medicine, Tokyo, Japan.

Please address correspondence to Hidenori Oishi, MD, PhD, Department of Neurosurgery, Juntendo University School of Medicine, 2-1-1 Hongo, Bunkyo-ku, Tokyo 113-8421, Japan; e-mail: ohishi@juntendo.ac.jp

http://dx.doi.org/10.3174/ajnr.A2858

\section{Materials and Methods}

\section{Patients and Aneurysms}

From June 2001 through December 2009, 599 patients with 653 UIAs underwent endosaccular coil embolization at the Juntendo University Hospital and affiliated hospitals. Among those, 457 patients with 500 small (maximum diameter $<10 \mathrm{~mm}$ ) asymptomatic UIAs comprised the patients of this study. Patients with dissecting or fusiform aneurysms, aneurysms treated with parent artery sacrifice, aneurysms associated with brain arteriovenous malformations, and mycotic aneurysms were excluded from the subjects. Small asymptomatic UIAs associated with ruptured aneurysms were included if the patients underwent endosaccular coil embolization of UIAs at least 3 months after the onset of $\mathrm{SAH}$ and were assessable without the influence of the $\mathrm{SAH}$ and/or the treatment of the ruptured aneurysm.

Table 1 shows the characteristics of patients and aneurysms. The size and neck width of the aneurysms were measured by conventional angiography. Procedure-related complications and immediate and follow-up clinical outcomes were assessed by the principal investigator (H.O.), incorporating the opinions of the coauthors according to the patients' medical records, outpatient charts, and operative records. The clinical outcome of each patient was assessed according to the mRS. ${ }^{5}$ Procedure-related complications were defined as neurologic deterioration, abnormal neuroimaging findings, and treatmentrelated undesirable events. The morbidity and mortality were defined as a deterioration of $>0$ on the mRS and any death related to the treatment. Clinical outcome and neurologic status were evaluated in 


\begin{tabular}{lcc}
\hline \multicolumn{3}{l}{ Table 1: Characteristics of patients and aneurysms } \\
\hline Characteristics & Data & $\%$ \\
\hline No. of patients & 457 & \\
Women & 333 & (72.9) \\
No. of aneurysms & 500 & \\
No. of patients with multiple aneurysms & 36 & (7.9) \\
$\quad \quad$ endovascularly treated & & \\
Age (yr) & $59.9 \pm 10.5$ & \\
$\quad$ Mean & 61.0 & \\
$\quad$ Median & $19-89$ & \\
$\quad$ Range & & \\
Aneurysm detection & 465 & (93.0) \\
$\quad$ Radiologic examinations for various reasons & 465 & \\
$\quad$ unrelated to aneurysms & & (7) \\
\hline
\end{tabular}

detail during every outpatient visit. The coauthors reviewed all the data. During the study period, 417 patients with 432 small asymptomatic UIAs were treated surgically; however, the number of aneurysms left untreated is unknown. Unfortunately, we could not collect or analyze the data of the UIAs surgically treated, for various reasons.

\section{Evaluation of Anatomic Outcome}

The principal investigator (H.O.) with the opinion of the coauthors conducted the evaluation of angiographic outcomes. The degree of aneurysm occlusion was defined by using the criteria previously described by Raymond et al. ${ }^{6}$ If there was no contrast filling of the dome, body, or neck of the aneurysm, it was defined as CO. If the contrast medium entered a part of the neck but did not fill the body and/or dome of the aneurysm, it was defined as $\mathrm{RN}$. If the contrast medium entered the body and/or dome of the aneurysm, it was defined as RA. Failure of endovascular therapy was defined as the impossibility of placing the coil or navigating the microcatheter into the aneurysm because of technical difficulties.

Our standard radiologic follow-up protocol is to perform MR angiography at 6 months and conventional angiography at 1 and 2 years after the endovascular therapy. MR angiography could be substituted for conventional angiography if the patient's condition was determined to be unsuitable or if the patient refused repeated conventional angiography. If the aneurysm occlusion was stable at the 2-year follow-up, the patient would undergo an MR angiography every year after that. We defined the change of aneurysm occlusion as the following: unchanged, the area of aneurysm filling was stable; minor recurrence, increased area of aneurysm filling, ideally without necessitating retreatment; major recurrence, increased area of aneurysm filling, necessitating retreatment; and improved, decreased area of aneurysm filling.

\section{Endovascular Procedures}

All the endovascular procedures were performed with the patient under general anesthesia. Systemic heparinization was initiated in all patients to maintain an activated clotting time from 250 to $300 \mathrm{sec}-$ onds throughout the procedure and was stopped at the end of the procedure for most patients. Patients were given aspirin, $100 \mathrm{mg}$, as an antiplatelet medication a few hours before the procedure, and it was continued daily for 1-2 months after the procedure to prevent thromboembolic events due to thrombus formation at the neck of coiled aneurysms. One or 2 working projections providing the best views of the aneurysm neck/body and microcatheter approach routes were decided on the basis of the images generated by the $3 \mathrm{D}$ reconstructed rotational digital subtraction angiography. If that was not available, 2D digital subtraction angiography in multiple projections was performed to obtain optimal working projections. After the procedure, angiograms in the frontal, lateral, and working projections were acquired to assess the degree of aneurysm occlusion and to rule out angiographically detectable thromboembolic events.

The simple technique using a single microcatheter was performed if a satisfactory aneurysm occlusion could be expected. Adjunctive techniques (balloon-assisted ${ }^{7}$ or double-catheter ${ }^{8}$ ) were used for aneurysms with unfavorable angioarchitecture for the simple technique. The appropriate sizes and shapes of coils were selected according to the target aneurysm. As our standard procedure, we inserted the coils within the aneurysm from the wall to the center as densely as possible or until another coil could no longer be inserted, without compromising the parent artery lumen, even after a complete angiographic obliteration was achieved.

\section{Devices Used}

One of the main brands of coils we used was the GDC (Boston Scientific, Natick, Massachusetts). We also used other brands of coils. The biologically modified coils (Matrix 2, Boston Scientific; Cerecyte, Micrus Endovascular, San Jose, California) were used in the 96 selected aneurysms treated after August 2008. The type of microcatheter we used in most of the procedures was a braided one (Excelsior SL10, Boston Scientific) with the tip manually steam-shaped. The navigation of the microcatheter into the aneurysm was basically performed with the assistance of a 0.012-inch microguidewire (GT wire; Terumo, Tokyo, Japan). We most often used an over-the-wire balloon microcatheter to perform the balloon-assisted technique (eg, HyperForm and HyperGlide, ev3, Irvine, California).

\section{Statistical Analysis}

Qualitative data are expressed as numbers and/or percentages. Mean values are presented as the mean \pm SD. Statistical analysis was performed by using the standard $\chi^{2}$ test with or without the Yates correction. Differences were considered significant at $P<.05$.

\section{Results}

\section{Aneurysm Characteristics}

A total of 449 aneurysms (89.8\%) were located in the anterior circulation, and $51(10.2 \%)$ were in the posterior circulation. Frequent locations were the siphon of the ICA, AcomA, MCA, and the PcomA in the anterior circulation and the BA bifurcation in the posterior circulation (Table 2).

The sizes of the aneurysms ranged from 2.0 to $9.5 \mathrm{~mm}$ in maximum diameter, with a mean size of $5.1 \pm 1.7 \mathrm{~mm}$. Aneurysm necks ranged from 1.0 to $6.5 \mathrm{~mm}$ in maximum diameter, with a mean size of $3.1 \pm 1.1 \mathrm{~mm}$. The $\mathrm{D} / \mathrm{N}$ ratios ranged from 0.71 to 4.0 , with a mean of $1.74 \pm 0.48$ (Table 3 ).

\section{Endovascular Therapy Feasibility}

Endosaccular coil embolization was completed in 481 aneurysms (96.2\%) and technically failed in 19 aneurysms (3.8\%) (Table 4$)$. The reasons for failure were: unfavorable $\mathrm{D} / \mathrm{N}$ ratio in $11(2.2 \%)$, wide neck in $5(1.0 \%)$, difficulty in preserving the branch originating from the aneurysm neck in $2(0.4 \%)$, and difficulty in navigating the microcatheter into the aneurysm due to the tortuosity of cervical and intracranial vessels in 1 $(0.2 \%)$. Procedures in all posterior circulation aneurysms were completed. Although there was a trend toward higher 


\begin{tabular}{|c|c|c|}
\hline Location & No. & $\%$ \\
\hline Anterior circulation & 449 & (89.8) \\
\hline Cavernous segment of ICA & 11 & (2.2) \\
\hline Siphon of ICA & 126 & (25.2) \\
\hline PcomA & 76 & (15.2) \\
\hline AChoA & 19 & (3.8) \\
\hline ICA bifurcation & 13 & (2.6) \\
\hline AcomA & 97 & (19.4) \\
\hline ACA & 26 & $(5.2)$ \\
\hline MCA & 81 & (16.2) \\
\hline Posterior circulation & 51 & $(10.2)$ \\
\hline BA bifurcation & 34 & (6.8) \\
\hline SCA & 8 & (1.6) \\
\hline PICA & 4 & (0.8) \\
\hline PCA & 4 & (0.8) \\
\hline BA trunk & 1 & (0.2) \\
\hline \multicolumn{3}{|c|}{ Note:-PCA indicates posterior cerebral artery; SCA, superior cerebellar artery. } \\
\hline \multicolumn{3}{|l|}{ Table 3: Aneurysm characteristics } \\
\hline \multicolumn{3}{|l|}{ Characteristics } \\
\hline Aneurysm size (mm) (mean) (range) & $5.1 \pm 1.7$ & $2.0-9.5$ \\
\hline$<5$ & 223 & $(44.6 \%)$ \\
\hline$\geq 5$ & 277 & (55.4\%) \\
\hline Aneurysm neck (mm) (mean) (range) & $3.1 \pm 1.1$ & $1.0-6.5$ \\
\hline$<4$ & 378 & $(75.6 \%)$ \\
\hline$\geq 4$ & 122 & $(22.4 \%)$ \\
\hline $\mathrm{D} / \mathrm{N}$ ratio & $1.74 \pm 0.48$ & $0.71-4.0$ \\
\hline$<1.5$ & 146 & $(29.2 \%)$ \\
\hline$\geq 1.5$ & 354 & $(70.8 \%)$ \\
\hline \multicolumn{3}{|c|}{$\begin{array}{l}\text { Table 4: Characteristics of } 19 \text { aneurysms with technically failed } \\
\text { treatment }\end{array}$} \\
\hline \multicolumn{3}{|l|}{ Location } \\
\hline$\overline{\mathrm{MCA}}$ & $9 / 81$ & $(11.1 \%)$ \\
\hline AcomA & $4 / 97$ & $(4.1 \%)$ \\
\hline PcomA & $2 / 76$ & $(2.6 \%)$ \\
\hline ACA & $2 / 26$ & $(7.7 \%)$ \\
\hline AChoA & $1 / 19$ & $(5.3 \%)$ \\
\hline ICA bifurcation & $1 / 13$ & $(7.7 \%)$ \\
\hline \multicolumn{3}{|l|}{ Aneurysm size (mm) } \\
\hline$<5$ & $12 / 223$ & $(5.4 \%)$ \\
\hline$\geq 5$ & $7 / 277$ & $(2.5 \%)$ \\
\hline \multicolumn{3}{|l|}{$\mathrm{D} / \mathrm{N}$ ratio } \\
\hline$<1.5$ & $12 / 146$ & $(8.2 \%)$ \\
\hline$\geq 1.5$ & $7 / 354$ & $(2.0 \%)$ \\
\hline
\end{tabular}

risk of failure in the MCA aneurysms, there were no significant differences between the locations. Failure according to aneurysm size was not statistically significant, but the $\mathrm{D} / \mathrm{N}$ ratio was statistically significant $(P<.05)$.

\section{Immediate Anatomic Outcome}

Table 5 shows the immediate angiographic outcomes according to the characteristics of the aneurysms. The aneurysms with a $\mathrm{D} / \mathrm{N}$ ratio of $\geq 1.5$ showed a high rate of $\mathrm{CO}$ and a low rate of RA $(P<.05)$. Table 6 shows the immediate angiographic outcomes according to the endovascular techniques. Aneurysms treated with the double-catheter technique showed a high rate of RA and a low rate of CO $(P<.05)$. Table 7 shows the immediate anatomic outcomes according to the types of coils used. There was no statistically significant difference between the bare coils and biologically modified coils.

\begin{tabular}{lcc}
\hline $\begin{array}{l}\text { Table 5: Immediate angiographic outcomes according to aneurysm } \\
\text { characteristics }\end{array}$ & $\%$ \\
\hline Outcome & $(n=481)$ & \\
\hline Overall & 309 & $(64.2)$ \\
CO & 72 & $(15.0)$ \\
RN & 100 & $(20.8)$ \\
RA & $(n=211)$ & \\
Aneurysms measuring $<5 \mathrm{~mm}$ & 134 & $(63.5)$ \\
CO & 24 & $(11.4)$ \\
RN & 53 & $(25.1)$ \\
RA & $(n=270)$ & \\
Aneurysms measuring $\geq 5 \mathrm{~mm}$ & 175 & $(64.8)$ \\
CO & 48 & $(17.8)$ \\
RN & 47 & $(17.4)$ \\
RA & $(n=134)$ & \\
D/N ratio $<1.5$ & 68 & $(50.7)$ \\
CO & 15 & $(11.2)$ \\
RN & 51 & $(38.1)$ \\
RA & $(n=347)$ & \\
D/N ratio $\geq 1.5$ & 241 & $(69.5)$ \\
CO & 57 & $(16.4)$ \\
RN & 49 & $(14.1)$ \\
RA & & \\
\hline
\end{tabular}

\begin{tabular}{|c|c|c|}
\hline \multicolumn{3}{|c|}{$\begin{array}{l}\text { Table 6: Immediate angiographic outcomes according to } \\
\text { endovascular techniques }\end{array}$} \\
\hline Technique/Outcome & & $\%$ \\
\hline Simple & $(n=190)$ & \\
\hline CO & 126 & $(66.3)$ \\
\hline RN & 24 & (12.6) \\
\hline RA & 40 & (21.1) \\
\hline Balloon-assisted & $(n=247)$ & \\
\hline $\mathrm{CO}$ & 166 & (67.2) \\
\hline $\mathrm{RN}$ & 40 & (16.2) \\
\hline RA & 41 & (16.6) \\
\hline Double-catheter & $(n=44)$ & \\
\hline $\mathrm{CO}$ & 17 & (38.6) \\
\hline RN & 8 & (18.2) \\
\hline RA & 19 & (43.2) \\
\hline
\end{tabular}

\begin{tabular}{|c|c|c|c|c|}
\hline \multirow[b]{2}{*}{ Outcome } & \multicolumn{2}{|c|}{ Bare Coil $(n=339)$} & \multicolumn{2}{|c|}{$\begin{array}{l}\text { Biologically } \\
\text { Modified Coils } \\
\quad(n=88)\end{array}$} \\
\hline & No. & $\%$ & No. & $\%$ \\
\hline \multicolumn{5}{|l|}{ Immediate } \\
\hline $\mathrm{CO}$ & 225 & (66.4) & 49 & $(55.7)$ \\
\hline $\mathrm{RN}$ & 49 & (14.5) & 19 & $(21.6)$ \\
\hline RA & 65 & (19.2) & 20 & $(22.7)$ \\
\hline \multicolumn{5}{|l|}{ Final } \\
\hline $\mathrm{CO}$ & 233 & (68.7) & 61 & (69.3) \\
\hline $\mathrm{RN}$ & 50 & (14.7) & 17 & (19.3) \\
\hline RA & 56 & (16.5) & 10 & $(11.4)$ \\
\hline
\end{tabular}

\section{Anatomic Follow-Up Outcomes}

A total of 427 aneurysms in 388 patients $(88.4 \%)$ underwent an anatomic follow-up by conventional angiography or MR angiography $\geq 6$ months after endovascular therapy. The mean anatomic follow-up period was $31.4 \pm 20.4$ months (range, 6.0-115.0 months). Table 8 shows the anatomic follow-up outcomes according to the aneurysm characteristics. Aneurysms measuring $<5 \mathrm{~mm}$ had a high rate of improve- 


\begin{tabular}{|c|c|c|c|c|c|c|c|c|}
\hline \multirow[b]{2}{*}{ Characteristics } & \multicolumn{2}{|c|}{ Unchanged } & \multicolumn{2}{|c|}{$\begin{array}{c}\text { Minor } \\
\text { Recurrence }\end{array}$} & \multicolumn{2}{|c|}{$\begin{array}{c}\text { Major } \\
\text { Recurrence }\end{array}$} & \multicolumn{2}{|c|}{ Improved } \\
\hline & No. & $\%$ & No. & $\%$ & No. & $\%$ & No. & $\%$ \\
\hline Overall $(N=427)$ & 272 & $(63.7)$ & 29 & (6.8) & 43 & $(10.1)$ & 83 & $(19.4)$ \\
\hline Aneurysms measuring $<5 \mathrm{~mm}(n=187)$ & 123 & (65.8) & 7 & (3.7) & 9 & (4.8) & 48 & (25.7) \\
\hline Aneurysms measuring $\geq 5 \mathrm{~mm}(n=240)$ & 149 & (62.1) & 22 & (9.2) & 34 & $(14.2)$ & 35 & $(14.6)$ \\
\hline $\mathrm{D} / \mathrm{N}$ ratio $<1.5(n=117)$ & 56 & (47.9) & 10 & (8.5) & 18 & (15.4) & 33 & $(28.2)$ \\
\hline $\mathrm{D} / \mathrm{N}$ ratio $\geq 1.5(n=310)$ & 216 & (69.7) & 19 & (6.1) & 25 & (8.1) & 50 & (16.1) \\
\hline
\end{tabular}

Table 9: Anatomic follow-up outcomes according to endovascular techniques

\begin{tabular}{|c|c|c|c|c|c|c|c|c|}
\hline \multirow[b]{2}{*}{ Technique } & \multicolumn{2}{|c|}{ Unchanged } & \multicolumn{2}{|c|}{ Minor Recurrence } & \multicolumn{2}{|c|}{ Major Recurrence } & \multicolumn{2}{|c|}{ Improved } \\
\hline & No. & $\%$ & No. & $\%$ & No. & $\%$ & No. & $\%$ \\
\hline Simple $(n=168)$ & 121 & (72.0) & 6 & (3.6) & 13 & (7.7) & 28 & $(16.7)$ \\
\hline Balloon-assisted $(n=222)$ & 139 & (62.6) & 19 & (8.6) & 21 & (9.5) & 43 & (19.4) \\
\hline Double-catheter $(n=37)$ & 12 & (32.4) & 4 & $(10.8)$ & 9 & (24.3) & 12 & (32.4) \\
\hline
\end{tabular}

\begin{tabular}{|c|c|c|c|c|}
\hline \multirow[b]{2}{*}{ Characteristic/Technique } & \multicolumn{2}{|c|}{ Ischemic } & \multicolumn{2}{|c|}{ Hemorrhagic } \\
\hline & No. & $\%$ & No. & $\%$ \\
\hline Aneurysms measuring $<5 \mathrm{~mm}$ & $8 / 223$ & (3.6) & $5 / 223$ & (2.2) \\
\hline Aneurysms measuring $\geq 5 \mathrm{~mm}$ & $11 / 277$ & (4.0) & $6 / 277$ & (2.2) \\
\hline $\mathrm{D} / \mathrm{N}$ ratio $<1.5$ & $10 / 146$ & (6.8) & $4 / 146$ & $(2.7)$ \\
\hline $\mathrm{D} / \mathrm{N}$ ratio $\geq 1.5$ & $9 / 354$ & (2.5) & $7 / 354$ & (2 \\
\hline Simple & $7 / 190$ & (3.7) & $4 / 190$ & (2.1) \\
\hline Balloon-assisted & $10 / 247$ & (4.0) & $5 / 247$ & (2.0) \\
\hline Double-catheter & $2 / 44$ & (4.5) & $1 / 44$ & (2.3) \\
\hline
\end{tabular}

ment, and aneurysms measuring $\geq 5 \mathrm{~mm}$ had a high rate of major recurrence $(P<.05)$. Aneurysms with a $\mathrm{D} / \mathrm{N}$ ratio of $<1.5$ had a high rate of major recurrence or improvement, and those with a $\mathrm{D} / \mathrm{N}$ ratio of $\geq 1.5$ had a high rate of being unchanged $(P<.05)$.

Table 9 shows the anatomic follow-up outcomes according to the endovascular techniques. The aneurysms treated with a double-catheter technique had a high rate of major recurrence/improvement and a low rate of being unchanged $(P<.05)$.

The final anatomic outcomes according to the types of coils used are shown in Table 7. There was no statistically significant difference between the bare coils and the biologically modified coils.

\section{Procedure-Related Complications}

Procedure-related complications occurred in 38 aneurysms $(7.6 \%)$. Nineteen aneurysms $(3.8 \%)$ had ischemic complications: ischemic findings on the MR or CT images in $11(2.2 \%)$, angiographically thromboembolic findings during the procedure in $5(1.0 \%)$, coil loop herniation with thrombus formation in the parent artery in $2(0.4 \%)$, and retinal artery branch occlusion in $1(0.2 \%)$. Ischemic complications occurred in 3 (5.9\%) of all posterior circulation aneurysms, 11 (4.5\%) of the ICA aneurysms, $3(3.7 \%)$ of the MCA aneurysms, and 3 (1.6\%) of the AcomA/ACA aneurysms. Eleven aneurysms (2.2\%) had hemorrhagic complications: intraprocedural aneurysmal rupture in $7(1.4 \%)$ and branch perforation by the microguidewire in $4(0.8 \%)$. Hemorrhagic complications occurred in 9 (7.3\%) AcomA/ACA aneurysms, 1 (1.2\%) MCA aneurysm, and $1(0.4 \%)$ ICA aneurysm. No hemorrhagic complications occurred in the posterior circulation aneurysms. The locations of aneurysms that ruptured during the procedure were the AcomA in $4(4.1 \%)$ and 1 each in the ACA (3.8\%), ICA-PcomA (1.3\%), and MCA (1.2\%). The risk of intraprocedural aneurysmal rupture was not significant regarding the location of aneurysms, but there was a trend toward a higher rupture incidence in AcomA aneurysms. In almost all patients with an intraprocedural aneurysmal rupture, the treatment consisted of immediate reversal of systemic heparinization and continuation of the expeditious insertion of coils to cause hemostasis. Only 1 patient had to undergo an urgent surgical clipping because an intraprocedural aneurysmal rupture occurred during the insertion of a framing coil without a balloon catheter. No clinical worsening was observed in any of the patients with an intraprocedural aneurysmal rupture.

Table 10 shows the ischemic and hemorrhagic complications according to the aneurysm characteristics and endovascular techniques. There were no significant differences between aneurysms measuring $<5 \mathrm{~mm}$ and those measuring $\geq 5$ $\mathrm{mm}$, but there was a significantly high risk of ischemic complications in aneurysms with a $\mathrm{D} / \mathrm{N}$ ratio of $<1.5(P<.05)$. There were no significant differences among the endovascular techniques.

Furthermore, the rates of intraprocedural aneurysmal rupture were $2.6 \%(2 / 78)$ and $1.2 \%(5 / 422)$ in aneurysms measuring $\leq 3$ and $>3 \mathrm{~mm}$, respectively. There was a trend toward a higher risk of intraprocedural aneurysmal ruptures in the very small aneurysms, but it was not statistically significant. The failure rates of the aneurysms $\leq 3 \mathrm{~mm}$ and $>3 \mathrm{~mm}$ were 
9.0\% (7/78) and 2.8\% (12/722), respectively, which were statistically significant $(P<.05)$.

There were other complications in the 8 remaining aneurysms (1.6\%): asymptomatic carotid artery dissection in 2 $(0.4 \%)$, and $1(0.2 \%)$ each of transient oculomotor nerve palsy, pseudoaneurysm formation at the groin puncture site, renal artery injury, transient cortical blindness, guidewire stretched and broken within the parent artery, and fatal pneumonia.

\section{Clinical Outcomes}

Five patients (1.1\%) had clinical worsening of the $\mathrm{mRS}$ of $>0$ within 30 days after endovascular therapy; their final mRS scores were $1,2,4,5$, and 6 . The causes of clinical worsening were ischemic events in 2 patients $(0.4 \%)$ and a hemorrhagic event, retinal artery branch occlusion, and severe pneumonia after general anesthesia leading to death in 1 patient $(0.2 \%)$ each. The permanent morbidity and mortality rates were $0.8 \%$ $(n=4)$ and $0.2 \%,(n=1)$, respectively. Clinical follow-up of $\geq 6$ months after endovascular therapy was available in 425 patients (93.0\%). No patients had aneurysmal SAH during the clinical follow-up period (mean, $34.7 \pm 2.9$ months; range, 6 months to 9.6 years).

\section{Retreatment of Coiled Aneurysms}

If the rupture risk of recurred aneurysms was considered equal or higher than that of the previous treatment, retreatment was indicated. Fourteen (2.9\%) of 481 aneurysms that had been technically completed underwent retreatment. Thirteen of those 14 aneurysms were treated with repeat endosaccular coil embolization. The 1 exception was an MCA aneurysm treated with surgical clipping. The duration between initial and repeated endovascular therapy ranged from 1.8 to 44.7 months (mean, 19.2 months). There was no morbidity or mortality related to the retreatment.

\section{Learning Curve}

Anatomic outcomes of the first 100 aneurysms showed $\mathrm{CO}$ in $61 \%, \mathrm{RN}$ in $6 \%$, RA in $22 \%$, and failure in $11 \%$; the last 100 aneurysms in our series showed CO in 53\%, RN in 15\%, RA in $31 \%$, and failure in only $1 \%$. The morbidity and mortality rates of the first 100 aneurysms showed $2.0 \%$ and $0 \%$, respectively; those of the last 100 aneurysms showed $0 \%$ and $1 \%$, respectively. There were no significant differences in either morbidity or mortality.

\section{Discussion}

The increase in radiologic examinations and the development of neuroimaging devices and techniques have resulted in frequent incidental detection of small asymptomatic UIAs. Severe aneurysmal SAH still causes high morbidity and mortality. ${ }^{9,10}$ Therefore, the prevention of aneurysmal rupture has been advocated as an effective treatment to reduce the morbidity and morality from aneurysmal SAH. Although the natural course and treatment-related risks of UIAs have been extensively investigated, the appropriate management of small asymptomatic UIAs remains controversial. Particularly, the risk of endovascular therapy of small asymptomatic UIAs needs further clarification.

\section{Natural Course of Small Asymptomatic UIAs}

The ISUIA study group investigators ${ }^{1}$ reported the results of a large retrospective multicenter study regarding the natural history of UIAs in 1449 patients with 1937 UIAs. They suggested that the rupture rates of aneurysms measuring $<10$ $\mathrm{mm}, 10-25 \mathrm{~mm}$, and $\geq 25 \mathrm{~mm}$ in patients with no history of SAH were $0.05 \%$, approximately $1 \%$, and $6 \%$, respectively; they concluded that small asymptomatic UIAs with no history of SAH have a benign natural course and a low risk of bleeding when left untreated. Furthermore, the ISUIA investigators ${ }^{2}$ reported that 5-year cumulative rupture rates of aneurysms measuring $<7 \mathrm{~mm}$ were $0 \%$ in the ICA, AcomA, ACA, or MCA and $2.5 \%$ in the posterior circulation or the PcomA. However, the limitations of the study included its retrospective nature, the short follow-up period, and a registration bias.

There are 2 articles in the literature on the rupture risk of UIAs in the Japanese population. Ishibashi et al ${ }^{11}$ reported the rupture risk in 419 patients with 529 UIAs with a mean follow-up duration of 905.3 days. The aneurysm size, history of $\mathrm{SAH}$, and location in the posterior circulation were significant risk factors. The aneurysmal rupture rates according to aneurysm size were $0.8 \%$ in small $(<4.9 \mathrm{~mm}), 1.2 \%$ in medium $(<9.9 \mathrm{~mm}), 7.1 \%$ in large $(>10 \mathrm{~mm})$, and $43.1 \%$ in giant $(>25 \mathrm{~mm})$ aneurysms. Sonobe et $\mathrm{al}^{3}$ reported the aneurysmal rupture rate of small $(<5 \mathrm{~mm})$ asymptomatic UIAs. In their report, 448 aneurysms in 374 patients were prospectively analyzed with the mean follow-up period of 41.0 months. The average aneurysmal rupture rates were $0.54 \%$ overall, $0.34 \%$ for single aneurysms, and $0.95 \%$ for multiple aneurysms.

\section{Comparison between Surgical Clipping and Endovascular Therapy}

An aggregate analysis of the literature by Lee et $\mathrm{al}^{12}$ in 2005 showed that the cumulative adverse outcome rates for endovascular therapy and surgical clipping of UIAs were $8.8 \%$ and $17.8 \%$, respectively. Alshekhlee et $\mathrm{al}^{13}$ studied the difference of hospital mortality rates between surgical clipping and endovascular therapy of UIAs from the National Inpatient Sample data base for the years 2000 thorough 2006 in US hospitals. They found that endovascular therapy was associated with low hospital mortality rates $(0.57 \%)$ compared with surgical clipping $(1.6 \%)$. According to the literature, the morbidity and mortality of endovascular therapy seem to be lower than those of surgical clipping. However, a true comparison between the risks of endovascular therapy and surgical clipping is difficult because of the differences in the characteristics of patients and aneurysms. Furthermore, the various physicians' technical skills and the degree of development of endovascular devices could not be evaluated objectively. To our knowledge, there are no reports directly comparing surgical clipping and endovascular therapy of small asymptomatic UIAs.

\section{Technical Complications}

Im et $\mathrm{al}^{4}$ reported results of endovascular therapy in 435 small asymptomatic UIAs. There were a total of 44 procedure-related complications (10.1\%): 24 thromboembolisms, 11 coil protrusions or herniations into the parent vessel, 4 intraprocedural aneurysmal ruptures, 3 device-related complications, and 2 femoral-access complications. In the ATENA study ${ }^{14}$ of a large volume of patients with 739 UIAs and 700 procedures 
conducted at 27 Canadian and French neurointerventional centers, the rates of thromboembolic events and intraprocedural aneurysmal rupture were $7.1 \%$ and $2.6 \%$, respectively. Standhardt et al ${ }^{15}$ reported $10.9 \%$ of thromboembolic events in 173 patients with UIAs treated by endovascular therapy. Five patients (3\%) in their study had strokes, including major and minor deficits ( $0.5 \%$ and $2.5 \%$, respectively).

Although the risk of thromboembolic events was low in the small UIAs (1-6 mm) in the ATENA study, ${ }^{14}$ the occurrence of thromboembolic complications was not significant regarding location, aneurysm size, or embolization technique. In our series, thromboembolic complications detected by CT as the main technique occurred in $3.8 \%$. Only the $\mathrm{D} / \mathrm{N}$ ratio of $<1.5$ was a significant risk factor of thromboembolic complications.

In the ATENA study, ${ }^{14}$ intraprocedural aneurysmal rupture was observed in 18 patients (2.6\%). Among those 18 patients, 5 manifested a permanent clinical aggravation, and 3 patients died. Gonzalez et $\mathrm{al}^{16}$ reported 3 intraprocedural aneurysmal ruptures $(1.4 \%)$ in 247 UIAs, and 1 patient died. In our series, intraprocedural aneurysmal rupture occurred in 7 aneurysms (1.4\%). All of the patients who had an intraprocedural aneurysmal rupture were discharged without any neurologic deficits. There have been a few reports that endovascular therapy of very small intracranial aneurysms $(\leq 3 \mathrm{~mm})$ has a high risk of intraprocedural aneurysmal rupture. ${ }^{4,17,18}$ In our series, the risk of intraprocedural aneurysmal rupture of very small aneurysms ( $\leq 3 \mathrm{~mm}$ ) was not significantly high. On the other hand, the failure rate was significantly high in the very small aneurysms. We speculate that physicians did not hesitate to abort the procedure to prevent an intraprocedural aneurysmal rupture if an abnormal delivery wire tension or unstable microcatheter position or both were recognized.

\section{Endovascular Therapy Feasibility}

Failure of the endovascular therapy of UIAs was reported in $5.0 \%-9.5 \% .^{10,19-22}$ In our series, failure occurred in $3.8 \%$ $(19 / 500)$, which is lower compared with that in previous reports. An unfavorable $\mathrm{D} / \mathrm{N}$ ratio of $<1.5$ is considered the most responsible factor.

\section{Morbidity and Mortality}

In the Wiebers et $\mathrm{al}^{2}$ ISUIA study, the mortality and morbidity rates at 30 days (defined as an mRS of 3-5 and impaired cognitive status) of 451 patients treated with endovascular therapy were $1.7 \%$ and $7.3 \%$, respectively. Lanterna et $\mathrm{al}^{23}$ reported a systematic review of the literature of 30 studies comprising 1379 patients with UIAs treated by endovascular therapy. They found that the overall permanent morbidity and mortality rates were $7 \%$ and $0.6 \%$, respectively. In the ATENA study, ${ }^{14}$ the 1 -month morbidity and mortality rates were $1.7 \%$ and $1.4 \%$, respectively. Im et $\mathrm{al}^{4}$ reported that the procedurerelated permanent morbidity rate of 358 small asymptomatic UIAs was $0.27 \%$ and the mortality was zero.

We strictly defined the "morbidity" as a change of mRS $>0$ and the "mortality" as all deaths during the perioperative period. Nevertheless, our morbidity and morality rates $(0.8 \%$ and $0.2 \%$, respectively) were comparable with those of previous reports. However, the morbidity and mortality in our series might be underestimated because the patients did not undergo an independent neurologic examination by a boardcertified neurologist before and after the endovascular therapy. Therefore, subtle neurologic deficits might have been missed. Furthermore, the cognitive status of the patients was not evaluated as it was in the ISUIA study.

\section{Anatomic Follow-Ups and Retreatments}

Im et $\mathrm{al}^{4}$ reported the anatomic follow-up results of 358 small asymptomatic UIAs by plain radiography and/or MR angiography and/or conventional angiography $\geq 6$ months after endovascular therapy. Stable aneurysm occlusion was achieved for $94.1 \%$, and recurrence occurred in $5.87 \%$. Only $1.7 \%$ of coiled aneurysms required retreatment. ${ }^{4}$ In our study, the recurrence rate was $16.9 \%$, and $2.9 \%$ of coiled aneurysms received retreatment. Particularly, aneurysms measuring $<5$ $\mathrm{mm}$ and/or with a $\mathrm{D} / \mathrm{N}$ ratio of $\geq 1.5$ had a low recurrence rate in the short-to-midterm period. These results suggest that with endovascular therapy of small asymptomatic UIAs, there is a low risk of recurrence and little need of retreatment. However, prospective studies with longer follow-up periods are warranted to definitively assess the true anatomic outcome.

\section{Effectiveness in Preventing Aneurysmal SAH}

Recurrence is a well-known drawback of endovascular therapy of intracranial aneurysms. Therefore, patients treated with endovascular therapy have to undergo long-term clinical and radiologic follow-up. Currently, it is unclear whether endovascular therapy actually reduces the bleeding risk of UIAs. Im et $\mathrm{al}^{4}$ reported that only 1 of 306 patients $(0.3 \%)$ with small coiled asymptomatic UIAs had aneurysmal SAH. Even though complete occlusion was achieved, a 5-mm MCA bifurcation aneurysm bled for 18 months after endovascular therapy. The patient was lost to clinical follow-up after initial treatment. Gallas et $\mathrm{al}^{19}$ did not experience posttreatment aneurysmal $\mathrm{SAH}$ in the 278 UIAs making up $77 \%$ of the aneurysms of $<10 \mathrm{~mm}$ endovascularly treated, with a mean follow-up period of 38 months. In our series, there were no patients who had aneurysmal SAH after endovascular therapy, with a mean follow-up of 34.7 months. These results suggest that endovascular therapy of UIAs, particularly that of small asymptomatic UIAs, provides sufficient protection from aneurysmal SAH in short-to-midterm periods. However, longer clinical and neuroimaging follow-up periods are mandatory to determine the accurate effectiveness of endovascular therapy in preventing aneurysmal SAH.

\section{Learning Curve}

Murayama et $\mathrm{al}^{24}$ reported their 11 years' experience of GDC embolization of cerebral aneurysms. They divided the subjects into 2 groups: group A included their initial 5 years' experience, and group B included the later 6 years' experience. Immediate angiographic outcome showed an increase in the rate of $\mathrm{CO}$ and a decrease in the occurrence of RN in group B. There were no significant differences in the rate of failure between groups A and B. They also found that group B was associated with an overall lower rate of technical complications than group A ( $7.3 \%$ compared with $11.3 \%$, respectively). Pierot et $\mathrm{al}^{25}$ compared the safety of endovascular therapy of UIAs between hospitals with a large volume of cases $(>20)$ and those with a small volume of cases $(\leq 20)$. They found that 
there were no significant differences regarding the clinical or anatomic outcomes between the 2 .

In our series, there was a high rate of failure in the first 100 aneurysms. Despite the fact that aneurysms with anatomic characteristics that presented a therapeutic challenge for endovascular therapy were treated among the later cases, the reasons for decreased failure seem to be related to the practitioners' technical advances and the development of the right devices.

\section{Limitations}

Because our study included retrospective data acquisition, a prospective study with a more rigorous technical and follow-up strategy is warranted. Because the anatomic and clinical outcomes and procedure-related complications were assessed by the authors, the results could be biased. We could not determine the safety or efficacy of the biologically modified coils because we mainly used bare platinum coils. The stentassisted technique was not assessed because intracranial stents had not been approved commercially in Japan during the study period. The patients in our series were not representative of the whole population of patients with small asymptomatic UIAs because surgically treated or untreated UIAs were not included in this study. Decisions regarding treatment indications may induce an inclusion bias.

\section{Conclusions}

The goal of this study was not to provide a conclusion about the treatment of small asymptomatic UIAs. However, it is conclusive that though the role of endovascular therapy as a prophylactic treatment remains controversial, it is highly feasible, with low morbidity and mortality rates.

\section{Acknowledgments}

We thank Robert E. Brandt (Founder, Chief Executive Office, and Continuing Medical Education, MedEd Japan) for his editorial assistance.

\section{References}

1. Unruptured intracranial aneurysms: risk of rupture and risks of surgical intervention-International Study of Unruptured Intracranial Aneurysms Investigators. N Engl J Med 1998;339:1725-33

2. Wiebers DO, Whisnant JP, Huston J 3rd, et al. Unruptured intracranial aneurysms: natural history, clinical outcome, and risks of surgical and endovascular treatment. Lancet 2003;362:103-10

3. Sonobe M, Yamazaki T, Yonekura M, et al. Small unruptured intracranial aneurysm verification study: SUAVe study, Japan. Stroke 2010;41:1969-77. Epub 2010 Jul 29

4. Im SH, Han MH, Kwon OK, et al. Endovascular coil embolization of 435 small asymptomatic unruptured intracranial aneurysms: procedural morbidity and patient outcome. AJNR Am J Neuroradiol 2009;30:79-84

5. Rankin J. Cerebral vascular accidents in patients over the age of 60. II. Prognosis. Scott Med J 1957;2:200-15

6. Raymond J, Guilbert F, Weill A, et al. Long-term angiographic recurrences after selective endovascular treatment of aneurysms with detachable coils. Stroke 2003;34:1398-403

7. Moret J, Cognard C, Weill A, et al. Reconstruction technic in the treatment of wide-neck intracranial aneurysms: long-term angiographic and clinical results-apropos of 56 cases [in French]. J Neuroradiol 1997;24:30-44

8. Kwon OK, Kim SH, Kwon BJ, et al. Endovascular treatment of wide-necked aneurysms by using two microcatheters: techniques and outcomes in 25 patients. AJNR Am J Neuroradiol 2005;26:894-900

9. Hop JW, Rinkel GJ, Algra A, et al. Case-fatality rates and functional outcome after subarachnoid hemorrhage: a systematic review. Stroke 1997;28:660-64

10. Raaymakers TW, Rinkel GJ, Limburg M, et al. Mortality and morbidity of surgery for unruptured intracranial aneurysms: a meta-analysis. Stroke 1998;29:1531-38

11. Ishibashi T, Murayama $Y$, Urashima $M$, et al. Unruptured intracranial aneurysms: incidence of rupture and risk factors. Stroke 2009;40:313-16

12. Lee $T$, Baytion $M$, Sciacca R, et al. Aggregate analysis of the literature for unruptured intracranial aneurysm treatment. AJNR Am J Neuroradiol 2005;26: 1902-08

13. Alshekhlee A, Mehta S, Edgell RC, et al. Hospital mortality and complications of electively clipped or coiled unruptured intracranial aneurysm. Stroke 2010; 41:1471-76

14. Pierot L, Spelle L, Vitry F. Immediate clinical outcome of patients harboring unruptured intracranial aneurysms treated by endovascular approach: results of the ATENA study. Stroke 2008;39:2497-504

15. Standhardt H, Boecher-Schwarz H, Gruber A, et al. Endovascular treatment of unruptured intracranial aneurysms with Guglielmi detachable coils: shortand long-term results of a single-centre series. Stroke 2008;39:899-904

16. Gonzalez N, Murayama Y, Nien YL, et al. Treatment of unruptured aneurysms with GDCs: clinical experience with 247 aneurysms. AJNR Am J Neuroradiol 2004;25:577-83

17. Brinjikji W, Lanzino G, Cloft $\mathrm{HJ}$, et al. Endovascular treatment of very small ( 3 mm or smaller) intracranial aneurysms: report of a consecutive series and a meta-analysis. Stroke 2010;41:116-21

18. Pierot L, Barbe C, Spelle L. Endovascular treatment of very small unruptured aneurysms: rate of procedural complications, clinical outcome, and anatomical results. Stroke 2010;41:2855-59

19. Gallas S, Drouineau J, Gabrillargues J, et al. Feasibility, procedural morbidity and mortality, and long-term follow-up of endovascular treatment of 321 unruptured aneurysms. AJNR Am J Neuroradiol 2008;29:63-68

20. Murayama Y, Vinuela F, Duckwiler GR, et al. Embolization of incidental cerebral aneurysms by using the Guglielmi detachable coil system. J Neurosurg 1999;90:207-14

21. Roy D, Milot G, Raymond J. Endovascular treatment of unruptured aneurysms. Stroke 2001;32:1998-2004

22. Wanke I, Doerfler A, Dietrich U, et al. Endovascular treatment of unruptured intracranial aneurysms. AJNR Am J Neuroradiol 2002;23:756-61

23. Lanterna LA, Tredici G, Dimitrov BD, et al. Treatment of unruptured cerebral aneurysms by embolization with Guglielmi detachable coils: case-fatality, morbidity, and effectiveness in preventing bleeding-a systematic review of the literature. Neurosurgery 2004;55:767-75

24. Murayama Y, Nien YL, Duckwiler G, et al. Guglielmi detachable coil embolization of cerebral aneurysms: 11 years' experience. J Neurosurg 2003;98: 959-66

25. Pierot L, Spelle L, Vitry F. Similar safety in centers with low and high volumes of endovascular treatments for unruptured intracranial aneurysms: evaluation of the analysis of treatment by endovascular approach of nonruptured aneurysms study. AJNR Am J Neuroradiol 2010;31:1010-14 